Viewpoint

\title{
Leveraging Healthcare Opportunities for Improved Access among Ghanaian Retirees: The Case of Active Aging
}

\author{
Delali A. Dovie \\ Sociology Department, University of Ghana, P.O. Box LG 65, Legon, Accra, Ghana; dadovie@st.ug.edu.gh \\ Received: 1 May 2018; Accepted: 31 May 2018; Published: 5 June 2018

\begin{abstract}
This paper is a policy brief with targeted interviews of older adults in urban Ghana with recommendations for future healthcare policy. Using qualitative explorative approach, the scope of the research is to examine opportunities that focus on healthy aging in order to enhance healthcare infrastructure in Ghana in preparation for an increased number of older adults. The paper mainly finds that improved healthcare solicitation and the social world of older adults are intricately linked. The healthcare needs of older adults are met through diverse mechanisms-the Pensioners' Medical Scheme and ceragim concept. These depict a transformation in healthcare access and delivery with implications for wider healthcare, solidarity and efficiency. Active ageing strategies therefore facilitate the provision of supplementary healthcare access by seeking health solutions independently, including the creation of awareness about the challenges and the concomitant health resource opportunities for older adults. These have the tendency for the development of an acumen for healthcare-related resilience. I argue that health-related challenges depict opportunities for smarter solutions and mutual growth, further showing that aging is gain and a human development issue that fosters the emergence of an integrated healthcare system. Crucially, the paper reveals that health-related challenges are used to leverage entry and participation in the healthcare products' market and by extension access to quality and holistic healthcare services. This encompasses innovative healthcare infrastructural resources that Ghanaian older adults patronize. These health resources are worth pursuing and may need to be incorporated into the National Policy on Ageing, with envisaged universal coverage in focus.
\end{abstract}

Keywords: retiree; voluntary associations; post-retirement life; active aging; healthcare

\section{Introduction}

Old age is plagued with a myriad of health challenges, namely bodily pains and weakness, eye problems, cancers, diabetes, poor eyesight, poor hearing, stroke, arthritis, rheumatism, including low physical activity (Adjetey-Soussey 2015; Kpessa-Whyte 2018). In sub-Saharan Africa, a rapidly aging population is presenting challenges to healthcare systems (Frost et al. 2014). The Centre for Ageing Studies (CFAS 2018) reports that a lot more older people than before are reporting disorders such as Alzheimers and other non-communicable diseases (NCDs) that could easily be managed (p. 5), for which there is the need for regular check-ups and treatments. Thus, increasingly, health insurance is becoming important in assisting people to deal with their health expenditures. It plays the role of mitigating the effects of healthcare expenditures (Adamba and Osei-Akoto 2015). Yet, Ghana's National Health Insurance Scheme (NHIS) does not cover all medical procedures and health services that may be required (Adjetey-Soussey 2015; Dovie 2018), leaving the aged in a disadvantageous state. However, in the coming decades the unprecedented demographic pressure (Gløersen et al. 2016) that Ghana will experience will leave little space for erroneous policies in the future. 
It is a fact that the number of older adults will continually increase in Africa at large and Ghana in particular (Mcintyre 2004). For example, it is projected that in Sub-Saharan Africa, the number of people aged 65+ will increase by approximately 10 million or increase by 57\% between 1999 and 2015 . As a consequence, there will be a heightened need to provide for their health and general well-being. Yet, in developing countries including Ghana, there are limited resources for general medical care. The major concern of researchers, clinicians, stakeholders and the entire society is how to have policies and adequate infrastructure and resources in place to adequately address the aging population's needs when it arises (CFAS 2018, p. 5). Hence, this study explores the innovative healthcare infrastructural resources that Ghanaian older adults patronize. The study, therefore, sought to answer the following questions: What opportunities exist for older adults to improve their health conditions? What role does a social association play in this process of seeking improved healthcare?

The remainder of the paper is structured as follows: The next section presents background to the study. This is followed by a section on the dynamics of social networking, active ageing and theoretical underpinnings of the study. Next is the methods section. The subsequent sections present and discuss healthcare related active ageing as well as conclude the paper.

\section{Background: The Ghanaian Case}

This section reflects on changing demographics in Ghana; the current healthcare system, social supports available in Ghana associated with aging; challenges and opportunities including compression of morbidity.

\subsection{Changing Demographics in Ghana}

The current population of Ghana is estimated to be 29.46 million, up from the official 2010 census figure of 24.2 million (World Population Review 2018). The majority of the people are within the 15 to 59 year group, and the elderly constitute less than $8 \%$ of the entire population. The youthful nature of the population is influenced by factors such as high rates of fertility and declining mortality especially among infants (Ghana Statistical Service (GSS 2012)).

Noteworthy is that due to migration and socio-economic progress and development, more than $50 \%$ of the population now lives in urban areas. The age structure is undergoing gradual transitions as adolescents and young adults grouped in the ages 15-24 have experienced systematic increases from 1.1 million in 1960 to 2.3 million, 3.5 million, and 4.9 million in 1984, 2000, and 2010 respectively (GSS 2013). Similar changes have also been observed in persons aged between 25 and 59 years. The proportion of persons in this age bracket constituted 30.6\% of the total population in 1970, it increased to $33.1 \%$ in $2000,35 \%$ in 2010 .

The cohort of the population under 15 years is expected to decrease further to $22.3 \%$ as the elderly population witness an upward movement to $14.1 \%$ in 2050 . It has also been projected that the proportion of persons 80 years and older will continue to increase and peak at $1.4 \%$ in the next three decades. In addition, the median age of the country's population is also expected to change in line with the general demographic trends. From a median age of 21 in 2010, Ghana is projected to enter into an intermediate population bracket with a median age of 21.5 years in 2020 and old population of 31.7 median age in 2050 (GSS 2013). The trend of aging also shows that the "coming decades will witness remarkable shifts in Ghana's population age structure towards older ages as a result of a decline in the proportion of children under 15 years" (Mba 2010, p. 5).

\subsection{Current Healthcare System}

The Government of Ghana (GOG) established the NHIS under Act 650 in 2003 (GCR 2007; Abebrese 2011). The scheme was launched in order to " ... provide basic healthcare services to persons resident in the country through mutual and private health insurance schemes" (GCR 2007, p. 19). It replaces the former cash and carry system which forced the people to pay money in cash when 
seeking medical attention at the hospital. The NHIS covers in-patient emergency, transfer services and out-patient care.

The NHIS is financed by the subscriber's premium-2.5\% National Health Insurance Levy of Social Security and National Insurance Trust (SSNIT) deductions from the formal sector-funds from GOG to be allocated by parliament including returns from investments (Abebrese 2011). Registration and renewal of NHIS are free for people aged 70+ (GCR 2007; Tonah 2009; Abebrese 2011; Doh et al. 2014; Adamba and Osei-Akoto 2015; Adjetey-Soussey 2015). Registration for and renewal of NHIS has been categorized into SSNIT contributors and non-SSNIT contributors. The former are given a discount of ( $\mathbb{C} 5.00$ which is equivalent to $\$ 1.1$ ) taken directly by SSNIT whilst the latter pay the full premium without any discount of ( $\mathbb{C} 30.00$ which is equivalent to $\$ 6.81)$. Yet, this policy is flawed at two distinct points namely that the stipulated diseases covered under this policy excludes payment for treatment of poor eyesight, poor hearing, hypertension, diabetes and a host of others. However, these are diseases that affect older people on a single or multiple basis.

\subsection{Social Supports Available in Ghana}

Previous research on aging has revealed that the protection that is provided to Ghanaian older adults has been under some kind of pressures from various factors such as modernization, urbanization as well as the search for better livelihoods (Tonah 2009; Mba 2010). The incipient formal support system, however, proffers the following support attributes. First, the Livelihoods Empowerment against Poverty (LEAP) (Abebrese 2011; Doh et al. 2014) provides target groups including older adults with cash transfers in support of their basic needs. Second, the social pension scheme currently expressed in Act 766 of 2008, a three-tier pension scheme, enables workers to prepare towards old age income security (Dovie 2017; Kpessa-Whyte 2018). However, this is limited in scope because of low coverage particularly among informal sector workers (Kpessa-Whyte 2018). Third, a 30\% property rebate exists for people aged $60+$ for Tema residents who own houses (Dovie 2017, 2018). Fourth, the 'EBAN card' component serves people aged 65+ with the bid to improve access to transportation built into the nation's Metro Mass Bus system and banking services. It offers transportation fares at half the cost to cardholders (Dovie 2017). Fifth, senior citizens' day was first marked in October 2003 (GCR 2007; Tonah 2009) and ever since then has been held on a yearly basis. The day is marked with the organization of health walks and health screening exercises such as eye screening (GCR 2007) for older adults. Finally, the national aging policy promotes social, economic and cultural re-integration of older adults into mainstream society in order to enable them to fully participate in national development as well as social life, yet not ignoring their fundamental rights (Tonah 2009; Doh et al. 2014; Adjetey-Soussey 2015). However, the institutional body which should be the kingpin — the National Aging Council—whose mandate it is to coordinate and facilitate these, is yet to be established.

\subsection{Challenges and Opportunities Associated with Aging}

Increased numbers of older adults present benefits as well as challenges for any given society. On one hand, they provide a wealth of skills, mentorship and wisdom and on the other hand, the environment, healthcare systems and their finances are not well adapted to support the nation's aging population (CFAS 2018, p. 3).

The challenges that older adults are faced with may be physiological, social, health, economic and psychological in nature. The health problems entail hearing, vision, kidney and bladder, heart and lungs, digestive problems, arthritis, stroke, and dementia (Ayete-Nyampong 2015). The social challenges relate to stereotyping. United Nations Population Fund (UNFPA) posits that ultimately the level of poverty among older adults is high. Older adults have also been subjected to cruel treatments that are socio-culturally oriented. For example, older adults from Northern Ghana are often accused of witchcraft and the attendant punishment is banishment from their respective communities. In consequence, they are ostracized, stigmatized, deserted and subjected to neglect by their family 
relations. The prospects of aging are expressed in terms of wisdom (Tonah 2009), rich accumulated experiences (Novak 2006), assisting with the care of grandchildren (Kpessa-Whyte 2018) and other relations, enabling focus on economic activities. This suggests that older adults contribute to the welfare of the family by virtue of their assistance in the raising, education and the impartation of indigenous wisdom and traditional values to their grandchildren. They also support the performance of household chores if good health permits. This attests to the existence of a "complex system that includes reciprocal care and assistance among generations with older people not only on the receiving end but also fulfilling an active, giving role" (Apt 2002, p. 41). Wisdom makes older adults skillful in their daily endeavors (Novak 2006). Hence, "more older people thinking and advising about practical problems could enhance quality of life for everyone" (p. 139).

\subsection{Compression of Morbidity}

Acute diseases such as tuberculosis, acute rheumatic fever, smallpox, diphtheria, tetanus, poliomyelitis, pneumococcal pneumonia in children and a host of others accounted for the key threats to health. However, there is a tremendous decline in these arrays of diseases due to improved nutrition, less crowded living arrangements, and water sterilization including immunization. This denotes a replacement of acute diseases with chronic ones. The latter comprises coronary-artery disease and stroke, arthritis, diabetes, cancer and cirrhosis. These are the predominant and major health problems in recent times (Fries 1980). Fries et al. (2011) note that osteoporosis, hypertension, or hyperlipidaemia are often not morbid conditions although they are chronic diseases. In essence, there is the likelihood to view progress in healthcare as an exchange of acute medical problems for chronic ones as indicated earlier. For which reason, "a person who survives an illness that appears early in life will have more lingering problems later" (p. 248). It is also worth noting that the postponement of chronic illnesses culminates in the rectangularization of both the mortality and morbidity curves. Yet, the "exchange of acute illnesses for chronic ones has resulted in a massive need for additional medical services" (p. 248). In this case, health improvement should focus on chronic diseases, morbidity, quality of life and postponement. Further, as Hubert et al. (2002) and Fries et al. (2011) have pointed out, healthier lifestyles result in the reduction and postponement of disability.

\section{Social Networking, Active Aging and Theoretical Underpinnings}

Social security programs comprise multifaceted roles, such as associations which have been helpful across all ages, particularly at the tail end of the life-course. This has become significant even in the face of changing family and social structures. This is further due to the rising costs of healthcare systems owing perhaps to new pharmaceuticals and technologies (McKinnon 2016), the evolving health burden associated with the rise in NCDs as well as increasing long-term care needs of aging societies (De Graft Aikins 2005; De Graft Aikins et al. 2016; McKinnon 2016; CFAS 2018). Older adults are socially engaged in social activities by virtue of their participation in the pensioners' association. Clearly, this is apparent in terms of meeting sustainable development goal 3-ensure healthy lives and well-being for all at all ages.

One major use of social networks entails how social networks influence the flow of, for example information or innovation, financial support among others. Scott (2017) argues that "a network of connections can provide help, support opportunities and even a sense of well-being that would not otherwise be possible" (p. 2). From a sociological perspective, social networks also entail digital and online networks including networks such as face-to-face relationships, political associations and connections and economic transactions among business enterprises including geopolitical relations.

According to Zaidi (2015), active and healthy aging depicts "growing older in good health and as a full member of society, feeling more fulfilled and in social engagements, more independent in our daily lives and more engaged as citizens" (p. 2). This is feasible and has been successful with support from government and relevant agencies (e.g., National Pensioners' Association (NPA) at the national, local communities and personal levels). At the level of the government, active aging comprises 
fostering employment, promoting social participation and engagement, increasing financial security, improving health and well-being including age-friendly infrastructure among others. Active aging strategies at the relevant agency level pertain to the facilitation of the provision of supplementary healthcare access. Finally, at the personal level, it entails fostering a healthy lifestyle by seeking health solutions independently. The strategies of active aging relate to changing attitudes and developing a more positive approach to handling aging related challenges, namely health problems.

The health dimension of active aging among older Ghanaian adults is best understood using Bronfenbrenner (1979) theoretical framework of ecological systems theory. This theory comprises four components-microsystem, mezzosystem, exosystem, and macrosystem. The microsystem component includes individuals and their families, the mezzosystem component includes neighbourhoods, the exosystem component includes organizations (e.g., government, NPA), and the macrosystem includes overall culture. Of key significance in this study are the microsystem and exosystem. Therefore, the theoretical barriers that affect service access utilization in Ghana have been broken down as follows. The microsystem component covers the following barriers: (1) self-reliant attitude; (2) religious beliefs; (3) alternative treatments among others. The mezzosystem component entails (1) lack of bilingual/bicultural professionals and (2) location and accessibility of (mental) health services. The exosystem component covers barriers such as (1) system bias; (2) lack of information; and (3) current practices. The macrosystem component is constituted by cultural barriers. The microsystems dimension articulates alternative treatment at the individual level that finds expression in health resources such as Pensioners Medical Scheme (PMS) and the ceragim concept.

The ceragim concept denotes physical activities and exercises organized in a gym like atmosphere. It epitomizes engagement in physical activities in an indoor context. It is a context in which individuals undergo regimented processes of exercise such as aerobics, massaging, and other forms of exercise using technology and associated gargets. For instance, the massaging bed works at the spinal cord area of individuals.

\section{Research Methods}

I espouse qualitative methodologies to explicate active aging and experiences based on the privilege of knowledge construction from the subjectivities of individual actions including to empower or give voice to individuals to share their stories.

\subsection{Subjects and Setting}

I recruited older adults aged $60+$ who have had a range of different experiences such as experience of NHIS exemption; government's assistance; and assistance from social capital. Tema in the Greater Accra region was the study site, chosen because the study aims at investigating active aging in an urban setting. The site was selected because it presents a web of social relations, a variety of activities: diverse events provide interesting and richer data. I recruited participants opportunistically and through a snowballing process across a myriad of social and alternative healing settings. The University of Ghana's Institutional Review Board approved the project. Confidentiality and anonymity were ensured.

\subsection{Interview Process}

I used two methods to gather data. Key informant and individual interviews (Table 1). These were employed because I needed to collect very detailed information from a smaller number of older adults for depth. Key informant interviews were conducted with two participants to explore active aging among older adults in Ghana from a healthcare viewpoint. The key informant interviews tapped into institutional and/or associational dynamics in relation to access to healthcare services. The key informant interviews examined structural expansion and process in the health system. In order to gather subjective accounts of illness practice, individual interviews were conducted with participants. Ten individual interviews were conducted with study participants to ascertain individual biographies 
and provide the requisite data for the development of an understanding of the relationships between social actors and their choice of illness practices. This provided insight into active aging among older Ghanaian adults. Table 2 shows the demographics of the people who participated in the key informant and individual interviews. The analysis identified three kinds of healthcare products-biomedical, supplementary biomedical and the ceragim concept. The participants privileged these healthcare products and articulated them as their ideal self-care practice. Yet, the psychosocial impact of old age-oriented illnesses and healthcare access drove cure seeking and healthcare indicative of active aging.

Table 1. Participant distribution and data collection method.

\begin{tabular}{ccc}
\hline \multirow{2}{*}{ Method } & \multicolumn{2}{c}{ Participants' Gender } \\
\cline { 2 - 3 } & Males & Females \\
\hline Key informant interviews & 2 & - \\
Individual interviews & 7 & 5 \\
\hline
\end{tabular}

Table 2. Participant demographics.

\begin{tabular}{ccccccc}
\hline Res & Pseudonyms & Gender & Age & Marital Status & Education & Occupation \\
\hline R1 & Georgina & Female & 66 & Divorced & Technical & Businesswoman \\
R2 & Joe Adinkrah & Female & 74 & Married & Tertiary: Diploma & Retiree \\
R3 & Kofi Jones & Male & 67 & Widower & Middle School & Retiree \\
R4 & Naky & Male & 62 & Married & Middle School & Retiree \\
R5 & Maame Afua & Female & 74 & Widowed & Middle School & Retiree \\
R6 & Essuman & Male & 69 & Remarried & Middle School & Retiree \\
R7 & Gina & Female & 65 & Separated & Tertiary: Diploma & Retiree \\
R8 & Nana Ewusi & Male & 73 & Married & Tertiary & Social worker \\
R9 & Kofi Mensah & Male & 65 & Married & Never attended school & Businessman \\
R10 & Merley & Female & 61 & Divorced & Post-secondary & Trader \\
R11 & Nii Amon & Male & 82 & Married & Tertiary & NPA official \\
R12 & Kotey & Male & 75 & Married & Tertiary & NPA official \\
\hline
\end{tabular}

Note: Res denotes respondent.

The interviews lasted between 45 and $90 \mathrm{~min}$. The interview guides were piloted to ensure accuracy in understanding, fluency and proper wording of questions. The face-to-face interviews were conducted in both the English and Ghanaian languages, namely Ga, Ewe and Twi. I audiotaped and transcribed the interviews. Interviews were conducted during the 2015/2016 academic year by the author.

I used multiple strategies to build validity and trustworthiness of the findings. Reliability of the instruments was also facilitated by the proper wording of questions. After the interviews were completed, the transcripts were shared with two independent individuals for their reviews through a systematic checking process including sameness of themes. Similarly, a second person also transcribed the interview data in lieu of quality assurance. The description of themes could be transferred to specific situations beyond this study, hence ensuring an extent of transferability. Dependability was ensured by subjecting the research process to clear descriptions and therefore could be audited. Thus, confirmability was enhanced by this act of transparency.

\subsection{Qualitative Data Analysis}

The key informant and individual interviews were preliminarily analyzed as they were being collected based on which modifications were made in the sampling strategy before the next series of interviews to ensure gaps were ascertained and rectified. This act preserved the multivocality and complexity of lived experiences while maintaining focus on the study's theme. The qualitative data analysis process was undertaken following Bryman (2008) analysis strategies. A combination of the following analytic strategies was employed in this paper. First, analytic induction which was related 
to reaching general explanations. Second, thematic analysis pertained to the examination of theoretical themes or hypotheses of a research through studying particular cases. Finally, narrative analysis was used to search for new themes or issues from the stories told by the research participants about their lives.

In this research, the six major themes identified from the literature review constituted the backbone for analyzing the data collected from fieldwork in Urban Ghana in support of thematic analysis technique. The analysis process was aided by the application of the framework method in which matrix-based comparisons such as comparative tables were undertaken. The framework table offered detailed analysis of the data within a particular theme. This therefore provided a clearer and deeper understanding of key themes within the context of the study. Efficiency of the thematic analysis carried out was ensured following a variety of principles in the course of data processing namely: repetition in search of issues that are commonly repeated by interviewees; and non-repetition in search of issues that were rarely mentioned by the interviewees; similarity and difference in a search of similar and different responses among interviewees on a given theme such as the frequency of health resource patronage; metaphor in a search of issues that are used in forms of metaphors; transitions in search of issues that link themes and sub-themes together. Theory linkage in search for linkage or connections to the outcome of research findings. These were undertaken to ensure the pursuance of the relationship between categories and themes of data, seeking to increase the understanding of the phenomenon.

Further, Nvivo Software was used to facilitate coding text and retrieving coded text as well as interpret the data. Using the Nvivo software, the analytical process proffered by Bazeley and Jackson (2014) were followed. The NVivo software was employed in this study in order to obtain rigor in dealing with such data using five distinct steps. The first step was the creation of a project which comprised all the documents, coding data and related information that assisted in the process of data analysis as well as saving the NVivo project. Second, the transcribed audio-recorded interview files were named respectively. The third step entailed working with qualitative data files which entailed the preparation of documents for import, following which the requisite documents that I intended to analyse were then imported. The fourth step was related to working with nodes. Nodes store is a place in NVivo for references to code text. Both tree and free nodes were created and used.

Fifth, in data coding, a chunk of data in a project document under a particular node was taken through the highlight of the requisite text using the mouse and pulling the highlighted text to the identified node using the coder. This included finding obvious themes as well as auto-coding. Subsequently, multiple codes were assigned to the same chunk of the text including going through the same process. The codes formed a pattern. The passage of texts was compared and contrasted for ways in which they were similar and different. The emergent concepts for example were all health concerns or responses: limited health access etc. Others were the dimension of the use of accessibility of healthcare services - cost, exemption, etc. The final step pertained to going further which encompassed the following: the start of analysis, going further with concepts, categories and themes including narrative and discourse. Memos were used to tell the story of the research by adding descriptions. The knowledge developed from the data was reported.

The outcomes of these activities were recorded in discussion memos. These strategies were integrated into the process of learning from the data. A thematic multi-case analysis was employed, the comparative focus of which was on individual cases as well as the preservation of their uniqueness. The goals of this type of analysis have been succinctly expressed by Miles and Huberman (1994) as follows:

One aim of studying multiple cases is to increase generalizability, reassuring yourself that the events and processes in one well-described setting are not wholly idiosyncratic. At a deeper level, the aim is to see processes and outcomes across many cases, to understand how they are qualified by local conditions, and thus to develop more sophisticated descriptions and more powerful explanations. 


\subsection{Condensing of Information and Development of Themes}

Further counts of a theme within the unstructured text were used as a proxy indicator of the significance of that theme for qualitative analysis. Codes were organized into categories (e.g., health challenges) and categories were organized into six themes including pensioners' health provision; social activities; physical activity; information source; healthy aging schemes; these are discussed in the results section. These themes appeared as major findings and were used to create headings in the results section of the paper (Creswell 2009). The interrelationship between themes involved the use of narrative passage to convey the findings of the analysis. The themes were interconnected into a storyline. Finally, use was made of tables to aid discussions. Patterns and relationships which were associative and/or causal were explored in the data. From these explorations, the researcher sought to understand how people construct meanings and actions, as preparations for understanding why people act the way they do (Charmaz 2006). Intervening, mediating or extraneous factors were also checked for regarding the focal concept's association, resistance as well as healthcare options. The final step entailed the selection, filtering and viewing of the predefined report for the study. All names used for research informants and interviewees are pseudonyms.

\section{Results: Active Aging Strategies}

\subsection{Concept Categories and Themes}

The concept categories obtained in the process of data analysis are pensioners' health provision; social activities; physical activity; information source; healthy aging schemes. Similarly, a list of primary themes was obtained from the concept categories/interviews. These themes have been categorized by topics such as social networking and their associated examples (See Table 3 for details).

Table 3. Primary themes and examples of responses.

\begin{tabular}{cl}
\hline Themes & \multicolumn{1}{c}{ Example Responses } \\
\hline Social networking & $\begin{array}{l}\text { We access information regarding older people at our monthly meetings and } \\
\text { socialize too. }\end{array}$ \\
\hline Active aging & It enhances engagement at old age, plus keeps me physically active. \\
\hline Coping strategies & It has facilitated increased access to healthcare for us. \\
\hline Alternative care sources & $\begin{array}{l}\text { It may serve as a preparatory mechanism for the phenomenon of } \\
\text { population aging. }\end{array}$ \\
\hline Health resource patronage & $\begin{array}{l}\text { I see NHIS, PMS and ceragim concept as complementary resources in terms } \\
\text { of usage. }\end{array}$ \\
\hline Resource recommendations/needs & $\begin{array}{l}\text { I believe it should be strongly encouraged. Absolutely! It is a timely resource in } \\
\text { preparation against increased older adult numbers. }\end{array}$ \\
\hline
\end{tabular}

\subsection{National Insurance}

Access to healthcare, which finds expression in the provision made with regard to the NHIS exclusively as well as the component inserted into Tier 1 of the national pension system are all aimed at ensuring comfortable post-retirement life in terms of healthcare including pension contributions.

\subsection{A Coping Strategy}

Participation in active aging activities encompasses belonging to associations such as social clubs or groups, health clubs and a host of others. The benefits of this participation include information relay, PMS and a host of others. The PMS is one based on participation in pensioners' association. It has been established with the aim of topping up the NHIS in lieu of the deficiencies in the latter's healthcare provision constituents and administration. This initiative is laudable considering the load of health challenges that older adults are faced with, even in an era of increased life expectancy and 
population ageing. The significance of this scheme is underscored by the disease load of older adults. This viewpoint is illustrated by Nii Amon as follows:

"The Pensioner Medical Scheme, you see ... is a Scheme which is a top up to the NHIS. You know, at this age ... from 65 years onwards, you contract so many diseases. You might not know yourself, but those diseases are of old age".

This initiative has become necessary because of reduced pension incomes, old age attendant health issues and the related costs. This brings to the fore the fact that healthcare is expensive in Ghana and therefore a big challenge for poorer older adults. As a result, participating members are required to contribute $\mathbb{C} 4.00$ per month (which is less than $\$ 1$ ) towards the Scheme, deducted from source-participants' monthly pension income in order to avoid inconsistencies in payment. This contribution is relatively small yet significant because of the category of people involved. However, these quotations do not take into account the issue of inflation and currency depreciation. It is also suggestive of a form of subsidized Scheme by looking at the quoted amounts involved. The following quote clearly articulates this:

You see the pension allowances are not so much to cater for our health needs, see so we have come together in the establishment of this scheme. Every month we contribute $\mathbb{C}_{4} .00$ each and at the end of the year you contribute $\mathbb{C}_{48.00}$. There are some diseases that when you go to Korle Bu or any other hospital they will charge you more than $\mathbb{C}_{2000.00}$... so you will realize that your money cannot cater for your sickness yourself. (Nii Amon, Key Informant Interviewee)

Interestingly, a participant can only commence receiving healthcare provision under the scheme a year after his/her contribution started. To fast-track healthcare provision under the Scheme, the initiators ensured the signing of the requisite contract to enable the rollout of the scheme. This, however, was done in two parts. The first part of the signing was done in northern Ghana, precisely Bolgatanga whilst the second took place in Accra, the southern part. During this, PMS cards were issued to participating members. This presupposes that the Scheme was first rolled out in the north before the subsequent roll out in the south including formally inaugurating it. The quote below demonstrates that:

As soon as you enter [join] and you have contributed for one year, they will start caring for you. So recently, we were at Bolga to sign the contract for the first phase of it but the whole thing started from the North. So at Bolgatanga also when this thing was launched formally they have the cards ...

(Nii Amon, Key Informant Interviewee)

Management of the Scheme's funds is undertaken by an organization known as Liberty Mutual Health, particularly because of their expertise in collaboration with the NPA. A note of caution needs to be sounded to the managers of the Scheme with regard to the quantum of diseases the Scheme is said to cater for, as this may have negative effects on its financial resources as well as its sustainability. This has been necessary due to observations from the monthly contributions paid per head. The promulgators of the Scheme have argued that they were over ambitious considering the number of diseases slated under it. Perhaps prior to the full implementation of the Scheme, it should have been piloted to help in streamlining inherent irregularities in the Scheme's system. This may have addressed the issue of feasibility of the disease for the treatment load it comprises. It would have also assisted in determining the actual chargeable cost per head.

There are some dissenting members who feel they are been charged exorbitant fees under the Scheme. The expression of these sentiments was followed by withdrawals of approximately 56 members from the Central region from the Scheme. However, the constitution of NPA has a strong stance against withdrawals by participating members, which may be a bit tyrannical and which may need to be reviewed to allow members to join the Scheme of their own free will and not by coercion. Noteworthy is that most of the withdrawn members returned and were asked to reapply to become members again. 
People are not happy with the amount we pay and they say it is too much and I have here the list of people from the Central region who have withdrawn themselves from it. But if you look at the constitution of the Association, then it means you shouldn't belong to the association again. They said they wanted to rejoin, so we asked them to apply formally again. They are about 56.. (Nii Amon, Key Informant interviewee)

Eligibility criteria for participation in the Scheme are in two forms. First, eligibility for participants is based on social security contribution without which eligibility is null and void. As a result, it has been argued that "this Association is meant for those who contributed towards SSNIT. If you don't get a SSNIT pension, you can't be a member" (Nii Amon, Key Informant Interviewee). Therefore, the citing of the charging of exorbitant fees presupposes that contribution to the Scheme is largely based on pension incomes, thus the issues raised above are suggestive of the meagre nature of (some) retirees' monthly pension incomes. A second eligibility criterion is to be a registered NHIS card holder. This is particularly critical because the Scheme as earlier indicated is a top up to NHIS, thereby filling the healthcare provision gaps in it to the extent possible. For instance, "yes, it is a top up. So compulsorily all members have National Health Insurance ... You see, so if you go to hospital whatever the NHIS cannot cater for the scheme shall top up." (Kotey, Key Informant Interviewee).

The diseases treated under the Scheme encompass "breast cancer for women, prostate cancer for men and then yearly screening." (Kotey, Key Informant Interviewee). The yearly screening is undertaken to ascertain what illnesses affect members. Some of them are very expensive and therefore the Scheme must take precautions not to mount them on their list of diseases, which makes it legally binding. These diseases require further research to ascertain the costs of their treatments. The Ministry of Health appears to be interested in the Scheme's activities and may attach their program to that of NPA in relation to the scheme. The Scheme's sustainability also depends on contributions from stakeholders from the general Ghanaian public. The effectiveness and efficiency of the Scheme may be boosted through socialization and social learning from countries with similar Schemes and the requisite expertise for older adults. This underscores the need to glean relevant knowledge from related countries.

Of all the diseases outlined, observations show that in Ghana hypertension is the number one disease that kills older adults more often due to the act of thinking extensively for various reasons including reduced incomes. For example, the following quote confirms this fact:

And then I was at a meeting and the report I was given about what is killing pensioners, you know, from SSNIT is hypertension. The people are thinking too much ... you see because some of them feel what they are getting is small. (Nii Amon, Key Informant interviewee)

The local agency used in this study is social network based. Thus, the NPA is constituted by contributors to social security, to which members belong automatically by virtue of their pension contributions irrespective of sector specificity albeit formal sector or informal sector. Being actively engaged with NPA activities has the added value of other benefits, namely property and sewerage rebate, all of which are aimed at ensuring comfortable post-retirement life in terms of healthcare, savings including pension contributions. With regard to house acquisition, if the house has already been acquired then the payment of property rate is what remains to be dealt with in post-retirement life. However, the property rate component has been given a reduced concession for people aged 60+, particularly for TMA residents. This Association has also been beneficial to participating members in terms of information dissemination and access, facilitating social interaction and solidarity. This entails access to a supplementary healthcare facility, which is an innovation hatched and inaugurated by the NPA. This innovation takes into account the inadequacies inherent in the state established and governed national healthcare system-NHIS. The innovative initiative by the NPA is suggestive of the awareness of the problems at hand-old age-related diseases and the gross inadequacies of health resources to help address these, especially since people live longer in contemporary times. 


\subsection{Alternative Care Sources}

The third pathway-the ceragim concept-is a healthcare seeking behavior that depends on physical activity as a treatment mechanism. It is constituted by the utilization of mechanical equipment with technological orientation in rendering healthcare products to patronizers. It is aimed at enhanced healthcare delivery to clients without age barriers, particularly older adults. It depicts the modernization of the administration of healthcare programs. The longer-run objective is for Ghana to construct a redistributive welfare system that is supportive of inclusive growth.

The ceragim concept is a highly visible paradigmatic shift that attempts to address health issues. In terms of how participants got information about the concept, different views were expressed ranging from introduction to the concept by friends in particular through to family relations. This has been illustrated by the following quotes:

I was introduced to ceragim at Community 7 after I complained to a friend about my swollen ankle region for which I sought orthodox treatment to no avail. (Naky, Male Individual Interviewee)

A family member introduced ceragim to me and from thereon I decided to stick to it as my way of aging gracefully by way of healthy living because on patronizing the facility, the body system goes through a regiment of body exercises in different shades. (Merley, Female Individual Interviewee)

The rate of patronage ranged from between once in a while to 6-7 months to 3 years. This may be dependent on the extent of health challenge and the urgency of treatment and/or healing required. These are demonstrated as follows:

I visited the facility for between 6-7 months and I have seen an improvement in the health conditions I have been battling with for a very long time. (Nana Ewusi, Male Individual Interviewee)

I had a health situation in which instead of being straight, my waist had shifted to the right side such that my body is more right oriented than previously was the case. But now my waist is straight likewise my entire body because of ceragim. Apart from this, I was not really feeling well in the entire members of my body system. For now, there is sanity in my body system. (Maame Afua, Female Individual Interviewee)

I was not really sick but I was introduced to the facility and I bought into the idea because I want to age actively and healthily. But then I do not attend or visit the facility regularly but I visit it all the same. (Kofi Jones, Male Individual Interviewee)

Equal numbers of older adults from both 60-69 and 70+ age categories patronized the ceragim concept. This suggests that even those who are privy to the NHIS exemptions also explored and patronized other health resources, which is however not surprising.

\subsection{Healthcare Resource Patronage}

The older adults patronized a collection of healthcare products simultaneously. This suggests that the participants used a medley of healthcare products for purposes of quick treatment outcomes and above all, healing. As column 3 of Table 4 illustrates, the majority of the older adults (50\%) combine two health products for use at any given point in time even in the case of NHIS exemption beneficiaries such as Joe. Hence the following statements:

I use NHIS. I also attend ceragim twice weekly—on Mondays and Thursdays. (Joe, Male Individual Interviewee)

I patronize NHIS and ceragim. (Georgina, Female Individual Interviewee)

I patronize the NHIS and ceragim. (Kofi Mensah, Male Individual Interviewee) 
The group of older adults who use all three of the resources outlined in the study, albeit NHIS, PMS and the ceragim concept at the same time is exemplified by the quote below:

I subscribe to and make use of a combination of the NHIS, PMS and the ceragim concept. (Kotey, Male Key Informant Interviewee)

Interestingly, the category of older adults who patronized two or three health resources cut across the 60-69 and 70+ age categories. Impliedly, some older adults mix biomedical health-seeking behavior with physical exercise as expressed in the ceragim concept. This is reminiscent of growing older healthily. These are summarized in Table 4.

Table 4. The pattern of healthcare patronage.

\begin{tabular}{ccc}
\hline Number of Resources & Number of Patronizers & Percentage (\%) \\
\hline 1 & 2 & 20 \\
2 & 5 & 50 \\
3 & 3 & 30 \\
\hline Total & $\mathbf{1 0}$ & $\mathbf{1 0 0}$ \\
\hline
\end{tabular}

The case of the usage of one health resource is typified by the quote below:

I worked at Barclays Bank limited and retired 7 years ago. When I got employed at Barclays, I was on a medical scheme over there. I have ever since been on the Barclays medical scheme. Using that I go for medical checks ups every year. (Gina, Female Individual Interviewee)

The PMS and ceragim concept are reflective of the varying roles played by non-state actors. "These act to influence the ability to achieve a seamless coordination of social policy intervention" (McKinnon 2016, p. 16). Ghana's healthcare system is biomedically colonized, thus it is an expanded healthcare system since the current medical management model predisposes people to healer shopping behavior. Participation in the PMS and the ceragim concept intimates that most people have lost confidence in the national healthcare system. Furthermore, care providers are hostile, a situation that further promotes healer shopping behavior among Ghanaians. Therefore, the PMS and the ceragim concept are significant additions to the Ghanaian healthcare model presently existent.

It is worth reiterating the fact that the NHIS covers a limited number of geriatric diseases whereas the pensioners' association medical care extends coverage to include prostate cancer, palliative care, osteoporosis, heart disease, high cholesterol, yearly screening complementarily. Physical activity yields fitness as an add-on to healthcare provision. The latter has fostered the uptake of technological usage and adaptation.

Health promotion entails improved diet or increased exercise which may reduce the onset of illness. However, the future for older adults may be far more high-tech than this due to technological revolution of bio-genetics, robotics, global communication and artificial intelligence. Given the role of education in securing healthcare opportunities, the urban older adults may be enjoying better conditions than their rural counterparts. I argue that ageing related health challenges depict opportunities for smarter solutions, and mutual growth, further showing that aging is a gain as well as a human development issue that fosters the emergence of an integrated healthcare system.

\section{Discussion}

Workers harness pension contribution as a pathway to healthcare delivery and access opportunities. Thus, the significance of pension contribution comes in two folds, namely eligibility for social infrastructures such as social interaction with age cohort-pensioners' association membership, property rebate, and above all NHIS and PMS. The pensioners' association membership dimension connotes the notion of participation in social networks and activities. This suggests a diverse 
web of relationships with fellow retirees which may be collaborative in nature, and from which several added benefits are obtained including additional healthcare access. This is consistent with Sarathchandra et al. (2018). Pluralistic and singular healthcare resource patronage is existent among older adults in Ghana. This has been facilitated by the limitation inherent in the NHIS with reference to age-based discrimination-the exemption factor. This has fostered the uptake of technological usage and adaptation with implications for aging well in relation to taking advantage of existing healthcare provision opportunities.

The pursuance of these health products such as PMS and ceragim concept by older adults is a reflection of social goals, the realization of which the social security system supports in terms of improving health outcomes while promoting higher levels of social inclusion. Support for this social goal is found in sustainable development goal 3 as mentioned earlier. The ceragim concept has gained widespread acceptance among a cross-section of Ghanaians. It necessitates engagement in physical activity of one form or another. Rogers et al. (2017) posit that maintaining a physically active lifestyle is beneficial. For instance, physical activity has the propensity to delay the onset and dampen frailty progression in older adults. Furthermore, in view of the conceptualization of chronic diseases and aging especially, "if loss of reserve function represents aging in some sense, then exercising an organ presents a strategy for modifying the aging process" (Fries 1980, p. 248). However, according to Huisingh-Scheetz et al. (2018) individuals clinically identified as frail are indeed at higher risk of having low activity. Other characteristics predict objective low activity as well or better. This may also entail lifestyle-related risk factors, including cigarette smoking, physical inactivity, and under- or overweight (Hubert et al. 2002).

The paper argues that improved healthcare solicitation and the social world of older adults are intricately linked, whilst the healthcare needs of older adults are met through diverse mechanismsthe PMS and ceragim concept. These depict a transformation in healthcare access and delivery. The emergence at the healthcare scene by PMS in the form of a quasi-private and private provision from the ceragim concept is to fill the healthcare deficiencies in the NHIS. This transformation from public to private provision will impact wider healthcare access as well as widespread disease load coverage particularly for low-income retirees with implication for solidarity and efficiency. A health system observes the principle of solidarity if it pays attention to the population's poorer strata's interest. To the contrary, the principle of efficiency anticipates the system to achieve optimum, given social and economic constraints.

From this tangent, therefore, older adults denote agents of development, including having made advances towards health and well-being. Older adults' engagement in active aging as situated in this paper expands the network of services available to older adults in essential areas such as health, housing and social welfare. Active aging here discussed has identified changes in the quality of life and socio-economic conditions of older adults (Sidorenko and Zaidi 2018) from the health dimension in particular. Age function related organizations such as the National Health Insurance Authority, Ministry of Gender, Children and Social Protection, NPA and a host of others need to collaborate to build genuine partnerships across sectors (Omimo et al. 2018). Increasingly, the effectiveness of delivery agencies is measured in terms of their outputs. At the same time, sustainability of the PMS may be facilitated with government's support through funding. The PMS may become the basis for the provision of health services to the informal sector if universal coverage is envisaged.

From individual responsibility and civic engagement dimension, it depicts the adoption of an active lifestyle, the maintenance of functional health and enhancement of the capacities (Loos et al. 2017, p. 61). This has implications for a reduction in the diverse negative consequences connoted with older adults, namely the marginalization of the process of growing old and social exclusion of older people. Loos (2013, pp. 26-27) provides the example of such a discourse in the Netherlands as follows:

Our increased life expectancy means that we will spend a long time in the 'third age', the period of retirement, while the 'fourth age' will be reduced to a short, painful descent 
into decay. It is striking that in the Netherlands especially public authorities make use of the concept of the 'third age'. The 'third age' receives ample mention in policy memorandums, while the 'fourth age' is quietly ignored.

However, according to Loos and Ekström (2014) the 'aging well' discourse is a consumerist marketing manoeuvre that makes old adult consumers treat aging as a controllable disease, instead of a natural universal process. For instance, the 'anti-aging' trend and healthy lifestyle are expressions of this approach that coerces consumers to take responsibility for their well-being, by taking control of their bodies while avoiding social exclusion (Vincent et al. 2008). In consequence, Ylänne et al. (2010) argue that consumers are faced with two options either to continuously attempt to control age-related 'problems' or to refuse to incorporate consumerist choices in their life as part of their well-being.

Inasmuch as aging well has facilitated healthcare innovations, it has challenges of its own. For instance, the 'aging well' or Andrews (2009) 'successful aging' discourse has been criticized on several tangents. The main criticisms of the 'aging well' discourse entail the following: First, the prejudicial association of aging with social withdrawal, that might cause self-denial and low self-esteem, and second, the 'false dualism' between the public self that is presented as agelessness and the private self, when admitting the inevitable age. This refers to the population at large, especially older adults. For example, a study conducted among University of Third Age (U3A) in Poland demonstrates the ways in which older members of U3A become the harshest critics of aging and old age (Wilińska 2012). Andrews (1999) notes that seduced by the discourse of agelessness, older adults engage in and promote activities that may be off the process of aging. Third, the 'aging well' discourse has the propensity to reinforce practices of ageism which operate at the intersection with other inequalities, such as male sexual performance and dominance as opposed to a woman's beauty.

Further, Liang and Luo (2012) opine that the 'aging well' discourse is also criticized for its cultural blindness (p. 329). The concept has been based on Western and North American values, which are dominated by success, independence, efficiency, sociability and wealth (Tornstam 2005) and has become a dominant discourse in Europe for the past 10 to 15 years (Foster and Walker 2014). However, Tornstam (2005) demonstrates that cultural differences exist regarding the essence of success, independence, efficiency, sociability and wealth. This also entails an individualistic versus collectivistic construction of self in a later age (Waid and Leslie 2003), all of which may play a role in different countries with respect to the meanings of 'aging well'. For instance, in Ghana, the cultural particularities of older adults' dependence on the extended family support system pertains-a collectivistic stance, whose decline has shaped the way later life is perceived, albeit shifting to newer ways of having needs including those of healthcare met outside the family domain while offering independence.

\section{Conclusions and Policy Recommendations}

This paper investigated the innovative healthcare infrastructural resources that older Ghanaian adults patronize in terms of which health-related literacy is used to leverage entry and participation in the healthcare products' market and by extension access to quality and holistic healthcare services. This is reminiscent of investment in healthy and active aging which has the tendency to enable individuals to live both healthier and longer lives for society to reap its dividends. A critical analysis of the healthcare opportunities that Ghanaian older adults take advantage of was undertaken. The significance of pensioners' association for retired Ghanaians fosters openness to healthcare opportunities. The utilization of active aging strategies is engaged in at three distinct points-government, local agency and personal levels.

The paper outlines how older adults garner diverse healthcare resources to meet their pertinent healthcare needs. Therefore, change is needed not only in practizing a greater degree of integration ... but also to ensure a focus on explicit strategic planning and management of ... (Omimo et al. 2018) all stakeholders namely governments, policy organizations, social security practitioners and healthcare providers to work together to proactively increase older adults' universal access to healthcare and 
delivery. Such an act may also take into account the development of financial vehicles that may, for instance, facilitate hedging against increases in longevity. This is critically significant yet virtually impossible with the status quo.

From the discussion above, a number of important trends can be identified: first expansion in NHIS coverage to the achievement of vertical equity is required as opposed to the situation where different healthcare services were offered to older adults of different ages. In which case, a universal healthcare service floor for all older adults will abolish the discrimination that presently exists. Second, health-related challenges ensured leveraging entry and participation in the healthcare products markets and by extension access to quality and holistic healthcare services. Thus, the paper revealed innovative healthcare infrastructural resources that Ghanaian older adults patronize.

The findings confirm Bronfenbrenner (1979) theory showing that at the microsystem level, alternative treatment facilitated the patronage of healthcare products. Similarly, from the mezzosystem component viewpoint, accessibility of healthcare services played a role in older adults' health-seeking behavior. Finally, the exosystem covered issues related to systematic bias in particular in opportunistic active aging in the area of healthcare.

The healthcare resources articulated in this paper, especially the PMS and the ceragim concept serve as add-ons to what Dovie (2018) refers to as an existing small-scale 'formal social infrastructure development' in Ghana, yet from parastatal and private dimensions. Using the Ghanaian experience as a case study, it is argued that the country's basic healthcare model inherent in the state welfare system holds value for low and middle-income countries who expect to enhance old age medical coverage and better mitigate poverty.

Policy recommendations are proffered with a focus on government and individual older adults. The road to a more stable, efficient and equitable health system in Ghana for older adults entails the policy omission discussed in this article including retirees' concomitant response in pursuing additional healthcare resources. A critical mass of political will to learn from past mistakes should perhaps follow. Two factors that may limit the sustainability of this trajectory to healthcare access are aging population and scarce financial resources, which have the propensity to create many social provisions. It is worth mentioning that certain restrictive eligibility criteria could be adopted in lieu of reducing fiscal costs while ensuring sustainability of the system. This may be undertaken via the adoption of means testing. In addition, the imposition of ex-ante means test of income or assets would have the potential of reducing the fiscal cost of basic healthcare for older adults in Ghana. Although its mainstay has been the preserve of the pension system, it is equally applicable to the health system. Furthermore, it is worth considering the adoption of ex-post income tax. The latter may be politically unpopular and less likely to materialize in Ghana.

The need to strengthen strategic policy advice has been a recurrent motivation. In the same vein, it is required that service quality must be updated including coverage. This has become necessary due to actuarial adjustments derivable from changes in average life expectancy, as well as the strong link between pensions and past contributions if that exists, a typical PMS is likely to increase the number of diseases covered for retirees' treatment access. Tacit here is an understanding that the realization of such a goal normally entails trade-offs, the choices pertaining to which will be determined by value judgments. In essence, politicians need to take older adults and their organization into account when considering what policies to support. Older adults have to adopt an active lifestyle, maintain functional health and enhancement of their capacities. They also need to adopt healthier lifestyles for onward reduction in potential disability.

The limitations of the study include the small sample of urban older adults, and specific characteristics of the Ghanaian cultural economy that may be pertinent to the conclusions and recommendations. 
Funding: This research was funded by [University of Ghana Next Generation of Academics in Africa Project Scholarship Award] grant number [UNFD/CC/061/2014-2015].

Acknowledgments: I would like to acknowledge the University of Ghana Staff PhD Research Grant for funding the project and the effort made by Vivian Gli in providing technical support on this paper.

Conflicts of Interest: The author declares no conflict of interest.

\section{References}

Abebrese, Joyce. 2011. Social Protection in Ghana: An Overview of Existing Programmes and Their Prospects and Challenges. Available online: http:/ / www.fesghana.org/index.php?page=new-publications (accessed on 23 October 2017).

Adamba, Clement, and Isaac Osei-Akoto. 2015. Positioning Ghana's Health Insurance System for Universal Coverage: A Synthesis of Strengths, Weaknesses, Opportunities and Threats. In Positioning Ghana: Challenges and Innovation. Edited by Nana A. Apt. Ibadan: Book Builders, Ibadan: Oluben Printers, pp. 219-46.

Adjetey-Soussey, Ebenezer. 2015. Getting Older People into the National Health Insurance Scheme. In Positioning Ghana: Challenges and Innovation. Edited by Nana A. Apt. Ibadan: Book Builders, Ibadan: Oluben Printers, pp. 247-66.

Andrews, Molly. 1999. The Seductiveness of Agelessness. Ageing E Society 19: 301-18.

Andrews, Molly. 2009. The Narrative Complexity of Successful Aging. International Journal of Sociology and Social Policy 29: 73-83. [CrossRef]

Apt, Nana Araba. 2002. Ageing and the changing role of the community: African perspective. International Social Security Review 55: 39-47. [CrossRef]

Ayete-Nyampong, Samuel. 2015. Aging in Contemporary Ghana. Accra: Paper and Ink Media.

Bazeley, Pat, and Kristi Jackson. 2014. Qualitative Data Analysis with Nvivo, 2nd ed. Sage: Thousand Oaks.

Bronfenbrenner, Uries. 1979. The Ecology of Human Development. Cambridge: Harvard University Press.

Bryman, Alan. 2008. Social Research Methods, 3rd ed. Oxford: Oxford University Press.

CFAS. 2018. Centre for Ageing Studies Newsletter. Legon: CFAS, pp. 1-14.

Charmaz, Kathy. 2006. Constructing Grounded Theory. Thousand Oaks: Sage.

Creswell, John W. 2009. Research Design, Qualitative, Quantitative and Mixed Method Approaches, 3rd ed. London: Sage Publications Inc.

De Graft Aikins, Ama. 2005. Healer Shopping in Africa: New Evidence from Rural-urban Qualitative Study of Ghanaian Diabetes Experiences. BMJ 331: 1-7.

De Graft Aikins, Ama, Mawuli Kushitor, Olutobi Sanuade, Samuel Dakey, Delali Dovie, and Joana Kwabena-Adade. 2016. Research on Aging in Ghana from the 1950s to 2016: A Bibliography and Commentary. Ghana Studies Journal 19: 173-89. [CrossRef]

Doh, Daniel, Stephen Afranie, and Ellen Bortei-Doku Aryeetey. 2014. Expanding Social Protection Opportunities for Older People in Ghana: A Case for Strengthening Traditional Family Systems and Community Institutions. Ghana Social Science Journal 11: 26-52.

Dovie, Delali A. 2017. Preparations of Ghanaian Formal and Informal Sector Workers towards Retirement. Unpublished Ph.D. dissertation, University of Ghana, Accra, Ghana.

Dovie, Delali A. 2018. Old Age Entitlements in Ghana: Reflections on MIPAA Adoption and the Way Forward. In Review and Appraisal of Country-Level Progress under MIPAA. Special MIPAA Issue 2, International Journal of Ageing in Developing Countries. In press.

Foster, Laim, and Allan Walker. 2014. Active and Successful Aging: A European Policy Perspective. The Gerontologist 55: 83-90. [CrossRef] [PubMed]

Fries, James F. 1980. Aging, Natural Death, and the Compression of Morbidity. The New England Journal of Medicine 303: 130-35. [CrossRef] [PubMed]

Fries, James F., Bonnie Bruce, and Eliza Chakravarty. 2011. Compression of Morbidity 1980-2011: A Focused Review of Paradigms and Progress. Journal of Aging Research 2011: 261702. [CrossRef] [PubMed]

Frost, Lucy, Liddie A. Navarro, Maeve Lynch, Mark Campbell, Miriam Orcutt, Anna Trelfa, Catherin Dotchin, and Richard Walker. 2014. Care of the Elderly: Survey of Teaching in an Aging Sub-Saharan Africa. Gerontology \& Geriatrics Education 2: 14-29. 
GCR. 2007. Ghana Country Report on the Implementation of the Madrid International Plan of Action on Aging. Available online: https://s3.amazonaws.com/ndpc-static/CACHES/NEWS/2015/07/10/ /Implementation+MIPAA_Ghana+Report.pdf (accessed on 20 September 2017).

Gløersen, Erik, Marius Drăgulin, Sebastian Hans, Jiannis Kaucic, Bernd Schuh, Florian Keringer, and Pietor Celotti. 2016. The Impact of Demographic Change on European Regions. European Union Committee of Regions Brussels, European Union-Committee of the Regions. Available online: http:/ / www.europa.euandhttp: / / www.cor.europa.eu (accessed on 1 March 2018).

GSS. 2012. 2010 Population and Housing Census: Summary Report of Final Results. Accra: Ghana Statistical Service. GSS. 2013. 2010 Population and Housing Census: National Analytical Report. Accra: Ghana Statistical Service.

Hubert, Helen B., Daniel A. Bloch, John W. Oehlert, and James F. Fries. 2002. Lifestyle Habits and Compression of Morbidity. The Journals of Gerontology Series A Biological Sciences and Medical Sciences 57: M347-M351. [CrossRef]

Huisingh-Scheetz, Megan, Kristen Wroblewski, Masha Kocherginsky, Elbert Huang, William Dale, Linda Waite, and Philip Schumm. 2018. The Relationship between Physical Activity and Frailty among U.S. Older Adults Based on Hourly Accelerometry data. The Journals of Gerontology Series A Biological Sciences and Medical Sciences 73: 622-29. [CrossRef] [PubMed]

Kpessa-Whyte, Michael. 2018. Aging and Demographic Transition in Ghana: State of the Elderly and Emerging Issues. Gerontologist 58: 403-8. [CrossRef] [PubMed]

Liang, Jiayin, and Baozhen Luo. 2012. Toward a Discourse Shift in Social Gerontology: From Successful Aging to Harmonious Aging. Journal of Aging Studies 26: 327-34. [CrossRef]

Loos, Eugène F. 2013. Designing for Dynamic Diversity: Representing Various Senior Citizens in Digital Information Sources. Observatorio (OBS*) Journal 7: 21-45.

Loos, Eugène F., and Monika Ekström. 2014. Visually Representing the Generation of Older Consumers as a Diverse Audience: Towards a Multidimensional Market Segmentation Typology. Participations 11: 258-73.

Loos, Eugène, Loredana Ivan, Mireia Fernández-Ardèvol, Maria Sourbati, Maria Ekström, Monika Wilińska, Simone Carlo, and Ioana Schiau. 2017. Ageing well? A Cross-country Analysis of the Way Older People are Visually Represented on Websites of Organizations for Older People. Journal of Comparative Research in Anthropology and Sociology 8: 63-83.

Mba, Chuks. 2010. Population ageing in Ghana: Research Gaps and the Way Forward. Journal of Aging Research 2010: 1-8. [CrossRef] [PubMed]

Mcintyre, Di. 2004. Health policy and older people in Africa. In Living Longer: Ageing, Development and Social Protection. Edited by Peter Lloyd-Sherlock. London: Zed Books.

McKinnon, Roddy. 2016. Introduction: Pursuing Excellence in Social Security Administration. International Social Security Review 69: 5-18. [CrossRef]

Miles, Matthew B., and Michael A. Huberman. 1994. Qualitative Data Analysis: An Expanded Sourcebook. Thousand Oaks: Sage.

Novak, Mark. W. 2006. Issues in Ageing. Boston: Pearson.

Omimo, Anthony, Dorah Taranta, Laura Ghiron, Charles Kabiswa, Sono Aibe, Millicent Kodande, Caroline Nalwoga, Samuel Mugaya, and Pamela Onduso. 2018. Applying ExpandNet's Systematic Approach to Scaling up in an Integrated Population, Health and Environment Project in East Africa. Journal of Social Sciences 7: 8. [CrossRef]

Rogers, Nina T., Alan Marshall, Chrissy H. Roberts, Panayotes Demakakos, Andrews Steptoe, and Scholes Shaun. 2017. Physical Activity and Trajectories of Frailty among Older Adults: Evidence from the English Longitudinal Study of Ageing. PLoS ONE 12: e0170878. [CrossRef] [PubMed]

Sarathchandra, Dilshani, Haltinner Kristin, Lichtenbe Nicole, and Tracyrg Hailee. 2018. It's Broader than Just My Work Here: Gender Variations in Accounts of Success among Engineers in U.S Academia. Social Sciences 7: 32. [CrossRef]

Scott, John. 2017. Social Network Analysis, 4th ed. London: Sage Publications Inc.

Sidorenko, Alexandre, and Ashgar Zaidi. 2018. International Policy Framework on Aging: Assessing progress in reference to the Madrid International Plan of Action on Ageing. The Journal of Social Policy studies 16: 141-54. [CrossRef]

Tonah, Steve. 2009. The Challenge of Ageing in Rural and Urban Ghana. In Contemporary Social Problems in Ghana. Edited by Steve Tonah. Accra: Yamens Press Limited.

Tornstam, Lars. 2005. Gerotranscendence: A Developmental Theory of Positive Aging. New York: Springer. 
United Nations Population Fund (UNFPA). 2012. Ageing in the Twenty-First Century: A Celebration and a Challenge. New York: UNFPA.

Vincent, John A., Emmanuelle Tulle, and John Bond. 2008. The Anti-ageing Enterprise: Science, Knowledge, Expertise and Values. Journal of Aging Studies 22: 291-94. [CrossRef]

Waid, Lisa D., and Frazer Leslie. 2003. Cultural Differences in Possible Selves during Later Life. Journal of Aging Studies 17: 251-68. [CrossRef]

Wilińska, Monika. 2012. Is There a Place for an Ageing Subject? Stories of Ageing at the University of the Third Age in Poland. Sociology 46: 290-305. [CrossRef]

World Population Review. 2018. Ghana Population 2018. Available online: http:/ /worldpopulationreview.com/ countries/ghana-population/ (accessed on 3 May 2018).

Ylänne, Virpi, Angie Williams, and Paul M. Wadleigh. 2010. Ageing well? Older people's Health and Well-being as Portrayed in UK Magazine Advertisements. International Journal of Ageing and Later Life 4: 33-62. [CrossRef]

Zaidi, Asghar. 2015. Active Ageing Index: A Legacy of the European Year 2012 for Active Ageing and Solidarity between Generations. In Policy Brief April 2015. Vienna: European Centre for Social Welfare Policy and Research.

(C) 2018 by the author. Licensee MDPI, Basel, Switzerland. This article is an open access article distributed under the terms and conditions of the Creative Commons Attribution (CC BY) license (http://creativecommons.org/licenses/by/4.0/). 